The Minok Planet No. 228. - The nearest ap roach to the earth's orbit made by any one of the 232 small planets so far known appears to occur in the case of No. 228, discovered by Herr Palisa at Vienna on August 19, 1882. At the perihelion point this planet may be distant from us only 0.662 of our mean distance from the sun, and on this account would prove a favourable object for a determination of solar parallax. But unfortunately the brightness of the planet at discovery was only $12.5 \mathrm{~m}$., though the mean anomaly was then $\mathbf{I}_{2}{ }^{\circ}$, or the perihelion passage took place five days subsequently. Hence it is very questionable if such an object could be utilised for the purpose. No. 132, Athra, has the smallest peribelion distance (1 6038), but in consequence of the large angle between the lines of nodes and apsides, and an inclination of nearly $25^{\circ}$, this planet is much further from the earth's track at perihelion than No. 228. Andromache, No. 175 , recedes furthest from the sun, the distance at aphelion being $4^{* 7234}$, or within 0.48 of the mean distance of Jupiter.

BINARY STARs.-According to Dr. Doberck's orbit of $\gamma$ Coronæ Borealis, this very difficult object should now be measurable with our larger instruments. For 1883.5 the calculated position is $123^{\circ}$, and the distance $\mathrm{o}^{\prime \prime} \cdot 34$. This object was single, with the great refractor at Washington, from 1875 to I879. In June, I88 $\mathbf{I}$, it was pronounced round, or doubtfully elongated, by Mr. Burnham, who remarks, "It has been apparently single with all apertures since about I87r." Doberck's period of revolution is $95^{\frac{1}{2}}$ years : periastron passage, $1843^{\circ} 7$.

The following calculated angles and distances of several other binaries may serve for comparison with obiervations :-

\begin{tabular}{|c|c|c|c|c|c|c|c|}
\hline Epoch. & Star. & & Position. & & Distance. & & $\begin{array}{l}\text { Authority } \\
\text { for orbit. }\end{array}$ \\
\hline $1882^{\prime} 5$ & $\ldots \eta$ Cassiopeiæ & $\cdots$ & 163.3 & $\cdots$ & $5 \cdot 52$ & $\cdots$ & Doberck. \\
\hline $1882 \cdot 5$ & .. $\xi$ Böotis & $\begin{array}{l}\cdots \\
\cdots\end{array}$ & $\begin{array}{l}161 \cdot 8 \\
268 \cdot 9\end{array}$ & $\begin{array}{l}\cdots \\
\cdots\end{array}$ & $\begin{array}{l}5 \cdot 38 \\
3 \cdot 56\end{array}$ & $\begin{array}{l}\ldots \\
. .\end{array}$ & $\begin{array}{l}\text { Duner. } \\
\text { Doberck. }\end{array}$ \\
\hline 1883.5 & $\cdots$, & . & $267 \cdot 6$ & $\ldots$ & 3.20 & $\ldots$ & , \\
\hline 188 & ... $\omega$ Leonis & & $86 \cdot 5$ & $\ldots$ & 0.60 & $\ldots$ & , \\
\hline 18835 & $\cdots \quad$, & $\ldots$ & $88 \cdot 2$ & $\cdots$ & 0.61 & $\cdots$ & , \\
\hline 1882.5 & $\ldots \eta$ Coronæ Bor. & $\cdots$ & 140.9 & $\ldots$ & 0.51 & $\cdots$ & , \\
\hline $1882^{\circ}$ & $\ldots \zeta$ Herculis & $\ldots$ & $105^{\circ} 9$ & $\ldots$ & $\mathbf{I} \cdot 43$ & $\cdots$ &, \\
\hline 80 & $\ldots \mu^{2}$ Herculis & $\ldots$ & $297 \cdot 3$ & $\ldots$ & 0.88 & $\cdots$ & ", \\
\hline 80 & $\ldots 70$ Ophiuchi & & 63 & & $2 \cdot 98$ & $\cdots$ & ser \\
\hline
\end{tabular}

\section{ELECTRICAL TRANSMISSION OF FORCE AND STORAGE OF POWER ${ }^{1}$}

$D R$. SIEMENS, in opening the discourse, reverted to the object the Council had in view in organising these occasional lectures, which were not to be lectures upon general topies, but the outcome of such special study and practical experience as Members of the Institution had exceptional opportunities of acquiring in the course of their professional occupation. The subject to be dealt with during the present session was that of electricity. Already telegraphy had been brought forward by Mr. W. H. Preece, and telephonic communication by Sir Frederick Bramwell.

Thus far electricity had been introduced as the swift and sultile agency by which signals were produced either by mechanical means or by the human voice, and flashed almost instantaneously to distances which were limited, with regard to the former, by restrictions imposed by the globe. To Dr. Siemens had been assigned the task of introducing to their motice electric energy in a different aspect. Although still giving evidence of swiftness and precision, the effects he should dwell upon were no longer such as could be perceived only through the most delicate instruments human ingenuity could contrive, but were capable of rivalling the steam engine, compressed air, and the hydraulic accumulator, in the accomplishment of actual work.

In the early attempts at magneto-electric machines, it was shown that, so long as their effect depended upon the oxidation of zinc in a battery, no commercially useful results could have been anticipitated. The thermo-battery, the discovery of Seebeck in 1822, was alluded to as a means of $c$ nverting heat into electric energy in the most direct manner; but this conversion could not be an entire one, because the second law of thermodynamics, which prevented the realisation as mechanical force of more than one-seventh part of the heat energy produced in

${ }^{1}$ Abstract of lecture given at the Institution of Civil Engineers on March 15 by Dr. C. William Siemens, F.R.S., M.Inst.C.E. Kevised by the author. combustiun under the boiler, applied equally to the thermoelectric battery, in which the heat, conducted from the hot points of juncture to the cold, constituted a formidable loss. The electromotive force of each thermo-electric element did not exceed 0.036 of a volt, and 1800 elements were therefore necessary to work an incandescence-lamp.

A most useful application of the thermoelectric battery for measuring radiant heat, the thermopile, was exhibited. By means of an ingenious modification of the electrical pyrometer, named the Bolometer, valuable researches in measuring solar radiations had been made by Prof. Langley.

Faraday's great discovery of magneto-induction was next noticed, and the original instrument by which he had elicited the first electric spark before the members of the Royal Institution in 1831, was shown in operation. It was proved that although the individual current produced by magneto-induction was exceedingly small and momentary in action, it was capable of unlimited multiplication by mechanical arrangements of a simple kind, and that by such multiplication, the powerful effects of the dynamo-machine of the present day were built up. One of the means for accomplishing such multiplication was the Siemens armature of 1856 . Another step of importance was that involved in the Pacinnoti ring, known in its practical application as the machine of Gramme. A third step, that of the self-exciting principle, was first communicated by Dr. Werner Siemens to the Berlin Academy, on January 17, 1867, and by the lecturer to the Royal Society on the $4^{\text {th }}$ of the following month. This was read on February 14, when the late sir Charles Wheatstone also brought forward a paper embodying the same principle. The lecturer's machine which was then exhibited, and which might be looked upon as the first of its kind, was shown in operation; it had done useful work for many years as a means of exciting steel magnets. A suggestion, contained in Sir Charles Wheatstone's paper, that "a very remarkable increase of all the effects, accompanied by a diminu. tion in the resistance of the machine, is observed when a cross wire is placed so as to divert a great portion of the current from the electro-magnet," had led the lecturer to an investigation read before the Royal Society on March 4, 1880, in which it was shown that by augmenting the resistance upon the electro-magnets a hundredfold, valuable effects could be realised, as illustrated graphically by means of a diagram. The most important of these results consisted in this, that the electromotive force produced in a "shunt-wound machine," as it was called, in creased with the external resistance, whereby the great fluctuations formerly inseparable from electric-arc lighting could be obviated, and that, by the double means of exciting the electromagnets, still greater uniformity of current was attainable.

The conditions upon which the working of a well-conceived dynamo-machine must depend were next alluded to, and it was demonstrated that when losses by unnecessary wire-resistance, by Foucault-currents, and by induced currents in the rotating armature were avoided, as much as 90 per cent, or even more, of the power communicated to the machine were realised in the form of electric energy, and that vice vers $\hat{a}$ the reconversion of electric into mechanical energy could be accomplished with similarly small loss. Thus, by means of two machines at a moderate distance apart, nearly 80 per cent. of the power imparted to the one machine could be again yielded in the mechanical form by the second, leaving out of consideration frictional losses, which latter need not be great, considering that a dynamo-machine had only one moving part weli balanced, and was acted upon along its entire circumference by propelling force. Jacobi had proved many years ago that the maximum efficiency of a magneto-electric engine was obtained when

$$
\frac{e}{E}=\frac{w}{W}=\frac{1}{2}
$$

which law had been frequently construed by Verdet ("Théorie Mécanique de la Chaleur") and others to mean that one-half was the maximum theoretical efficiency obtainable in electric transmission of power, and that one-half of the current must be necessarily wasted or turned into heat. The lecturer could never be reconciled to a law necessitating such a waste of energy, and had maintained, without disputing the accuracy of Jacobi's law, that it had reference really to the condition of maximum work accomplished with a given machine, whereas its efficiency must be governed by the equation

$$
\frac{e}{E}=\frac{z v}{W}=\text { nearly } \mathbf{r} \text {. }
$$

From this it followed that the maximum yield was obtained 
when two dynamo-machines (of similar construction) rotated nearly at the same speed, but that under these conditions the amount of force transmitted was a minimum. Practically the best condition of working consisted in giving to the primary machine such proportions as to produce a current of the same magnitude, but of 50 per cent. greater electromotive force than the secondary; hy adopting such an arrangement, as much as 50 per cent. of the power imparted to the primary could be practically received from the secondary machine at a distance of several miles. Prof. Silvanus Thompson, in his recent Cantor Lectures, had show $\mathrm{n}$ an ingenious graphical method of proving these important fundamental laws.

The possibility of transmitting power electrically was so obvious that suggestions to that effect had been frequently mare since the days of Volta, by Kitchie, Jacobi, Henry, Page. Hjorth, and others; but it was only in recent years that such transmission had been rendered practically feasible.

Just six years ago, when delivering his pre:idential address to the Iron and Steel Institute, the lecturer had ventured to suggest that " time will probably reveal to us effectual means of carrying power to great distances, but I cannot refrain from alluding to one which is, in my opinion, worthy of consideration, namely, the electrical conductor. Suppose water-power to be employed to give motion to a dynamo-electrical machine, a very powerful electrical current will be the re:ult, which may be carried to a great distance, through a large metallic conductor, and then be made to impart motion to electro-magnetic engines, to ignite the carbon points of electric lamps, or to effect the separation of metals from their combinations. A copper rod 3 inches in diameter would be capable of transmitting rooo h.p. a distance of say 30 miles, an amount sufficient to supply one quarter of a million candle-power, which would suffice to illuminate a moderately-sized town." This suggestion had been much criticised at the time, when it was still thought that electricity was incapable of being massed so as to deal with many horse power of effect, and the size of conductor he had proposed was also considered wholly inadequate. It would be interesting to test this early calculation by recent experience. Mr. Marcel Deprez had, it was well known, lately succeeded in transmitting as much as $3 \mathrm{~h}$. p. to a distance of 40 kilometres ( 25 miles) through a pair of ordinary telegraph wires of $4 \mathrm{~mm}$. diameter. The results so obtained had been carefully noted by Mr. Tresca, and had been communicated a fortnight ago to the French Academy of Sciences. Taking the relative conductivity of iron wire employed by Deprez, and the 3:inch rod proposed by the lecturer, the amount of power that could be transmitted through the latter would be about 4000 h.p. But Deprez had employed a motor-dynamo of 2000 volts, and was contented with a yield of 32 per cent. only of the power imparted to the primary machine, whereas he had calculated at the time upon an electromotive force of 200 volts, and upon a return of at least 40 per cent. of the energy imparted. In March, 1878, when delivering one of the Science Lectures at Glasgow, he said that a 2-inch rod could be made to accompli-h the object proposed, because he had by that time conceived the possibility of employing a current of at least 500 volts. Sir William Thomson had at once accepted these views, and with the conceptive ingenuity peculiar to himself, had gone far beyond him, in showing before the Parliamentary Electric Iight Committee of 1879 , that through a copper wire of only $\frac{1}{2}$-inch diameter, 21,000 h.p. might be conveyed to a distance of 300 miles with a current of an intensity of 80,000 volts. The time might come when such a current could be dealt with, having a striking distance of about $\mathbf{I}^{\circ} 2$ feet in air, but then, probably, a very practical law enunciated by Sir William Thomson would be infringed. This was to the eff, ct that eleciricity was conveyed at the cheapest rate through a con uctor, the cost of which was such that the annual interest upon the money expended equalled the annual expenditure for lost effect in the conductor in producing the power to be conveyed. It appeared that Mr. Deprez had not followed this law in making his recent installations.

Sir William Armstrong was probably first to take practical advantage of these suggestions in lighting his house at Cragside during night-tiue, and working his lathe and saw-bench during the day, by poner transmitted through a wire from a waterfall nearly a mile distant from his mansion. The lecturer had also accomplished the several objects of pumping water, cutting wood, hay, and swedes, of lighting his house, and of carrying on experiments in electro-horticulture from a common centre of steam-power. The results had been most satisfactory; the whole of the management had been in the hands of a gardener and of labourers, who were without previous knowledge of electricity, and the only repairs that had been found necessary were one renewal of the commutators and an occasional change of metallic contact brushes.

An interesting application of electric transmission to cranes, by Dr. Hopkinson, was shown in operation.

Amongst the numerous other applications of the electrical transmission of power, that to electrical railways, first exhibited by Dr. Werner Siemens, at the Berlin Exhibition of 1879 , had created more than ordinary public attention. In it the current produced by a dynamo-machine, fixed at a convenient station and driven by a steam-engine or other motor, was conveyed to a dynamo placed upon the moving car, through a central rail sup. ported upon insulating-blocks of woc d, the two working-rails serving to convey the return current. The line was 900 yards long, of 2 -feet gauge, and the moving car served its purpose of carrying twenty visitors through the Exhibition each trip. The success of this experiment soon led to the laying of the Lichterfelde line, in which both rails were placed upon insulating sleepers, so that the one served for the conveyance of the current from the power station to the moving car, and the other for completing the return circuit. This line had a gauge of 3 feet 3 inches, was 2500 yards in length, and was worked by two dynamo-machines, developing an aggregate current of 9000 Watts, equal to $\mathbf{2} 2 \mathrm{~h}$. p. It had now been in constant operation since May 16, 1881, and had never failed in accomplishing its daily traffic. A line half a kilometer in length, but of 4 feet $8 \frac{1}{2}$ inch gange, was established by the lecturer at Paris in connection with the Electric Exhibition of 1881. In this case two suspended conductors in the form of hollow tubes with a longitudinal slit were adopted, the contact being made by metallic bolts drawn through these slit tubes, and connected with the dynamo-machine on the moving car by copper ropes passing through the roof. On this line 95,000 passengers were conveyed within the short period of seven weeks.

An electric tramway 6 miles in length had just been com. pleted, connecting Portrush with Bush Mills in the north of Irelaud, in the installation of which the lecturer was aided by Mr. Traill, as engineer of the Com any, by Mr. Alexander Siemens, and by Dr. E. Hopkinson, representing his firm. In this instance the two rails, 3 feet apart, were not insulated from the ground, but were joined electrically hy means of copper staples and formed the return circuit, the current being conveyed to the ear through a $T$ iron placed upon short standards, and insulated by means of insulite caps. For the present the power was produced by a steam-engine at Portrusb, giving motion to a shunt-wound dynamo of 15 ,oco Watts $=20$ h.p., but arrangements were in progress to utilise a waterfall of ample power near Bush Mills, by means of three turbines of $40 \mathrm{~h} . \mathrm{p}$.seach, now in course of erection. The working-speed of thi line was restricted by the Board of 'Trade to Io miles an hour, which was readily obtained, although the gradients of the line were decidedly unfavourable, including an incline of 2 miles in length at a gradient of $I$ in 38 . It was intended to extend the Iine 6 miles beyond Bush Mills, in order to join it at Dervock station with the north of Ireland narrow-gauge railway system.

The electric system of propulsion was, in the lecturer's opinion, sufficiently advanced to assure practical success under suitable circumstances-such as for suburban tramways, elevated lines, and above all lines through tunnels, such as the Metropolitan and District Railways. The advantages were that the weight of the engine, so destructive of power and of the plant itself in starting and stopping, would be saved, and that perfect immunity from products of combustion would be insured. The limited experience at Lichterfelde, at Paris, and with another electric line of 765 yards in length, and 2 feet 2 inches gauge, worked in connection with the Zaukerode Colliery since October, 1882, were extremely favourable to this mode of propulsion. The lecturer however did not advocate its frospective application in competition with the locomotive engine for main lines of railway. For tramways within populous districts the insulated conductor involved a serious difficulty. It would be more advantageous under these circumstances to resort to secondary batteries, forming a store of electrical energy carried under the seats of the car itself, and working a dynamo-machine connected with the moving wheels by means of belts and chains.

The secondary battery $u$ as the only available means of propelling vessels by electrical power, and considering that these batteries might be made to serve the purpose of keel ballast, 
their weight, which was still considerable, would not be objectionable. The secondary battery was not an entirely new conception. The hydrogen gas battery suggested by Sir Wm. Grove in 1841 , and which was shown in operation, realised in the most ferfect manner the conception of storage, only that the power obtained from it was exceedingly slight. The lecturer, in working upon Sir William Grove's conception, had twenty-five years ago constructed a battery of considerable power in substituting porous carbon for platinum, impregnating the same with a precipitate of lead peroxidised by a charging current. At that time little practical importance attached, however, to the subject, and even when Planté, in I860, produced his secondary battery, composed of lead plates peroxidised by a charging current, little more than scientific curiosity was excited. It was only since the dynamo-machine had become an accomplished fact that the importance of this mode of storing energy had become of practical importance, and great credit was due to Faure, to Sellon, and to Volckmar, for putting this valuable addition to practical science into available forms. A question of great interest in connection with the secondary battery had reference to its permanence. A fear had been expressed by many that local action would soon destroy the fabric of which it was composed, and that the active surfaces would become coated with sulphate of lead preventing further action. It had, however, lately been proved in a paper read by Dr. Frankland before the Royal Society, corroborated by simultaneous investigations by Dr. Glad-tone and Mr. Tribe, that the action of the secondary battery depended essentially upon the alternative composition and decomposiţion of sulphate of lead, which was therefore not an enemy, but the best friend to its continued action.

In conclusion, the lecturer referred to electric nomenclature, and to the means for measuring and recording the passage of electric energy. When he addressed the British Association at Soutbampton, he had ventured to suggest two electrical units additional to those established at the Electrical Congress in $188 \mathrm{I}$, viz., the Watt and the Joule, in order to complete the chain of units connecting electrical with mecbanical energy and with the unit-quantity of heat. He was glad to find that this suggestion had met with favourable reception, especially that of the Watt, which was convenient for expressing in an intelligible manner the effective power of a dynamo-machine, and for giving a precise idea of the number of lights or effective power to be realised by its current, as well as of the engine power necessary to drive it : 746 Watts represented I h.p.

Finally the Watt-meter, an instrument recently developed by his firm, was shown in operation. This consisted simply of a coil of thick conductor suspended by a torsion wire, and opposed laterally to a fixed coil of wire of high resi-tance. The current to be measured flowed through both coils in parallel circuit, the one representing its quantity expressible in Ampères, and the sther its potential expressible in Volts. Their joint attractive action expressed therefore Volt-Amperes or Watts, which were read off upon a scale of equal divisions.

The lecture was illustrated by experiments, and by numerous diagrams and tables of results. Measuring instruments by Professors Ayrton and Perry, by Mr. Edison and by Mr. Boys were also exhibited.

\section{FAUNA AND FLORA OF THE ALEUTIAN ISLANDS}

THE last number of Naturen contains an interesting report by Dr. Leonhard Stejneger of the result of his six months observations of the fauna and flora of the Kamschatkan coast and of the so-called Kommandorski Islands, which form the western group of the Aleutian archipelago between Behring's Sea and the Pacific, in $50^{\circ}-55^{\circ} \mathrm{N}$. lat. The Kommandorski group consists of two islands, one of which is known as Medno Ostrov, Copper Island, from the large amount of the pure meta found there ; while the other, which was the scene of Behring's shipwreck and death, bears his name. Both islands are geologically allied to Kamschatka, and excepting at the north of Behring's Island, where the gradual subsidence of the sea has left raised beaches, terraces, and tabulated rock-formations, the islands consist generally of deep narrow valleys separated by rocky barriers, which rite precipitously to a beight of from 1000 to 2000 feet above the level of the sea. The islands, which were uninhabited before their annexation by Russia, are now occupied by about 700 persons, in the employment of a Russo-
American fur company, which has been attracted to the spot by the enormous numbers of sea-bears (Callorhinus ursinus) and sea-oiters (Enhydra lutris) which frequent the coasts. The climate is foggy, and the vegetation stunted and sparse, while in the neiyhbouring Kamschatkan territory the blue of the summer sky, the stillness of the sea, and the softness of the air, are almost Italian in character. The flora, moreover, is so exuberant that numerous plants, which in Norway never exceed two or three feet, here attain the height of a tall man. Next to the birch (Betula ermanni), alders, willows, and roans (Sorbus Kamschaticus), are the most frequent trees, the berries of the last-named, and those of Lonicera carrulea, $\mathrm{p}$ 'ssessing a sweetness which brings them into great request among strangers as well as natives. Some flowers also, as the wild, indigenous, dark red rose, several rh dodendrons, and native lilies, are s:qually remarkable for exceptional fragrance. Among wild flowers, some of the geraniums, potentillas, taraxacums, \&c., are almost identical with those found in Norway. Besides a large whale, and a specimen of the walrus (Rosmarus obesus), which had been killed near Avatscha Bay, Dr. Stejneger could find no trace of any mammal but a small specimen of Arvicola aconomus. Of birds there is, however, an enormous variety, some of which, as Calliope Kamschatica, Carpodacus Ery. thrinus, and a kind of sedge-warbler, provisionally named by the author "Acrocephalus dybowskii," combine an almost tropical brilliancy of colouring with a sweetness of song equal to that of our own nightingale or thrush. Besides these melodious warblers, Kamschatka harbours large numbers of Locustella lanceolata, whose grasshopper-like cry is heard when all else is still. Cuculus canorinus represents our common cuckoo. Pipits, chats, and wagtails abound; Larus capistratus is commoner than any other gull, and the osprey is not unfrequent. Mosquito.like gnats of vindictive nature swarm in such numbers as to make the pursuits of the field naturalist almost impracticable. The fauna, generally, is palæarctic in character, with a scarcity of American forms which is very remarkable when we consider the vicinity of the western continent.

\section{PHYSICAL HISTORY OF THE DEAD SEA, THE FORDAN VALLEY, AND PALESTINE}

PROF. E. HULL, LL.D., F.R.S., delivered an interesting lecture on the above subject on March 2, in the Theatre of the Royal Dublin Society's premises, Kildare Street. Prof. Hull said:- "There is no country which possesses for us an interest equal to that which I have to treat of this evenins. Its religious and historical associations stand alone amongst those of all nations, and will ever maintain in the history of the world an undying import. But while this is true as regards the religious and social aspects of Palestine, I hope to show that in its physical aspect it possesses points of interest which render it unique amongst all countries, and which have attracted to it the attention of naturalints during a lengthened period down to the present day. Probably no country has been so often described. Its physical features have attracted the attention of observers of natural phenomena from Strabo downwards to the recent admirable work of M. Lartet and the Duc de Luynes, to which I am largely indebted. In more recent times we have the observations of Humboldt, of the late Dr. Hitchcock, of Lieut. Lynch of the United States Navy; who carried out a systematic series of soundings over the bed of the Dead Sea, and more recently of the Rev. Dr. Tristram, of Prof. Roth, Burkhardt, and others, including the Survey made by the officers of the Royal Engineer:. It is curious however that the remarkable physical phenomenon which renders the Holy Land unique among:t all countries (regarded in its physical aspect) was not discovered till the year 1836-37, when Heinrich Von Schubert and Prof. Koth determined by barometric observations that the surface of the Dead Sea lies no less than 1300 feet below the level of the Mediterranean, a fact not suspected by previous observers. It is the deep depression of the Jordan Valley, deeper by far than any river valley elsewhere, which is the key to the physical history of the whole country; and in endeavouring to trace out its origin $I$ : hall reproduce in as general a manner as I can the successive phases through which the region bordering the Medittrranean, and extending eastwards towards the Euphrates and southwards to the Dead Sea, has passed. The fundamental basis of the geological formation of Palestine is the gneissic granite, of Archrean age and metamorphic origin, which rises into the mountains of Idumea, and is the rock from which the huge 